\title{
Acid-sensing ion channels: dual function proteins for chemo-sensing and mechano- sensing
}

Yuan-Ren Cheng ${ }^{1,2}$, Bo-Yang Jiang ${ }^{1,2}$ and Chih-Cheng Chen ${ }^{1,2,3^{*}}$

\begin{abstract}
Background: Acid-sensing ion channels (ASICS) are a group of amiloride-sensitive ligand-gated ion channels belonging to the family of degenerin/epithelial sodium channels. ASICs are predominantly expressed in both the peripheral and central nervous system and have been characterized as potent proton sensors to detect extracellular acidification in the periphery and brain.

Main body: Here we review the recent studies focusing on the physiological roles of ASICs in the nervous system. As the major acid-sensing membrane proteins in the nervous system, ASICs detect tissue acidosis occurring at tissue injury, inflammation, ischemia, stroke, and tumors as well as fatiguing muscle to activate pain-sensing nerves in the periphery and transmit pain signals to the brain. Arachidonic acid and lysophosphocholine have been identified as endogenous non-proton ligands activating ASICs in a neutral pH environment. On the other hand, ASICs are found involved in the tether model mechanotransduction, in which the extracellular matrix and cytoplasmic cytoskeletons act like a gating-spring to tether the mechanically activated ion channels and thus transmit the stimulus force to the channels. Accordingly, accumulating evidence has shown ASICs play important roles in mechanotransduction of proprioceptors, mechanoreceptors and nociceptors to monitor the homoeostatic status of muscle contraction, blood volume, and blood pressure as well as pain stimuli.
\end{abstract}

Conclusion: Together, ASICs are dual-function proteins for both chemosensation and mechanosensation involved in monitoring physiological homoeostasis and pathological signals.

Keywords: ASIC, ASIC3, Mechanotransduction, Nociceptor, Pain, Proprioception

\section{Background}

Sensing tissue acidosis and mechanical force is essential for an organism to respond to noxious stimuli and/or physiological changes for survival $[1,2]$. In vertebrates, primary sensory afferents of dorsal root ganglia (DRG), trigeminal ganglia (TG), and nodose ganglia (NG) project to tissues all over the body to detect tissue acidosis and monitor force changes from outside or inside the body [3, 4]. Tissue acidosis occurs during tissue injury, inflammation, ischemia, and metabolic changes, whereas force changes arise from tactile stimuli, muscle contraction, visceral organ movement, tooth movement, blood

\footnotetext{
* Correspondence: chih@ibms.sinica.edu.tw

${ }^{1}$ Department of Life Science, National Taiwan University, Taipei 106, Taiwan ${ }^{2}$ Institute of Biomedical Sciences, Academia Sinica, 128, Academia Rd. Sec. 2, Taipei 115, Taiwan

Full list of author information is available at the end of the article
}

and body fluid flow, etc. Chemoreceptors or metaboreceptors are sensory neuron subtypes responsible for sensing tissue acidosis; mechanoreceptors are the other subtypes for sensing force. In addition, polymodal nociceptors detect noxious tissue acidosis and noxious mechanical stimuli [5]. Accumulating evidence has revealed membrane proteins that allow sensory neurons to monitor tissue acidosis, including acid-sensing ion channels (ASICs), transient receptor potential (TRP) channels, ATP-gated ion channel (P2X), two-pore domain potassium (K2P) channels, and proton-sensing G-protein-coupled receptors (GPCR; e.g., G2A, GPR4, OGR1, TDAG8) [2, 6, 7].

However, mechanically activated ion channels that allow sensory neurons to transmit mechanical stimuli are not fully understood. Candidate mechanically activated ion channels include ASICs, K2P channels, PIEZO proteins, 
tentonin 3, transmembrane channel-like (TMC) proteins, TRP channels, and volume-regulated anion channel (VRAC) $[1,4,8,9]$. Some ion channels (e.g., ASICs, K2P, and TRP channels) seem to have dual protein functions in sensing both tissue acidosis and mechanical force. In this review, we focus on recent progress in research into ASICs and discuss how these ion channels are involved in acid-sensing and mechano-sensing functions of sensory neurons.

\section{Acid-sensing ion channels}

ASICs are members of the degenerin/epithelial sodium ion channel (DEG/ENaC) family, a group of voltage-insensitive cation channels expressing in the nervous system and many types of epithelial cells and immune cells [10] (Fig. 1).
In rodents and humans, four genes, including Accn1, Accn2, Accn3, and Accn4, encoding at least six ASIC subtypes (ASIC1a, ASIC1b, ASIC2a, ASIC2b, ASIC3, and ASIC4) have been reported [11, 12]. ASICs are known as proton-gated ion channels, because heterologously expressed ASIC1a, ASIC1b, ASIC2a, and ASIC3 are mainly permeable to $\mathrm{Na}^{+}$(and to a lesser extent $\mathrm{Ca}^{2+}, \mathrm{K}^{+}$) and mediate a transient or a biphasic (transient and sustained) inward current in response to external acidification.

Each ASIC subtype contains two transmembrane domains with intracellular $\mathrm{N}$ - and C-termini and a large extracellular loop. Crystallization of the chicken ASIC1a channel revealed that three subunits are required to form a functional channel. The subunit composition of a functional channel could be an assembly of three

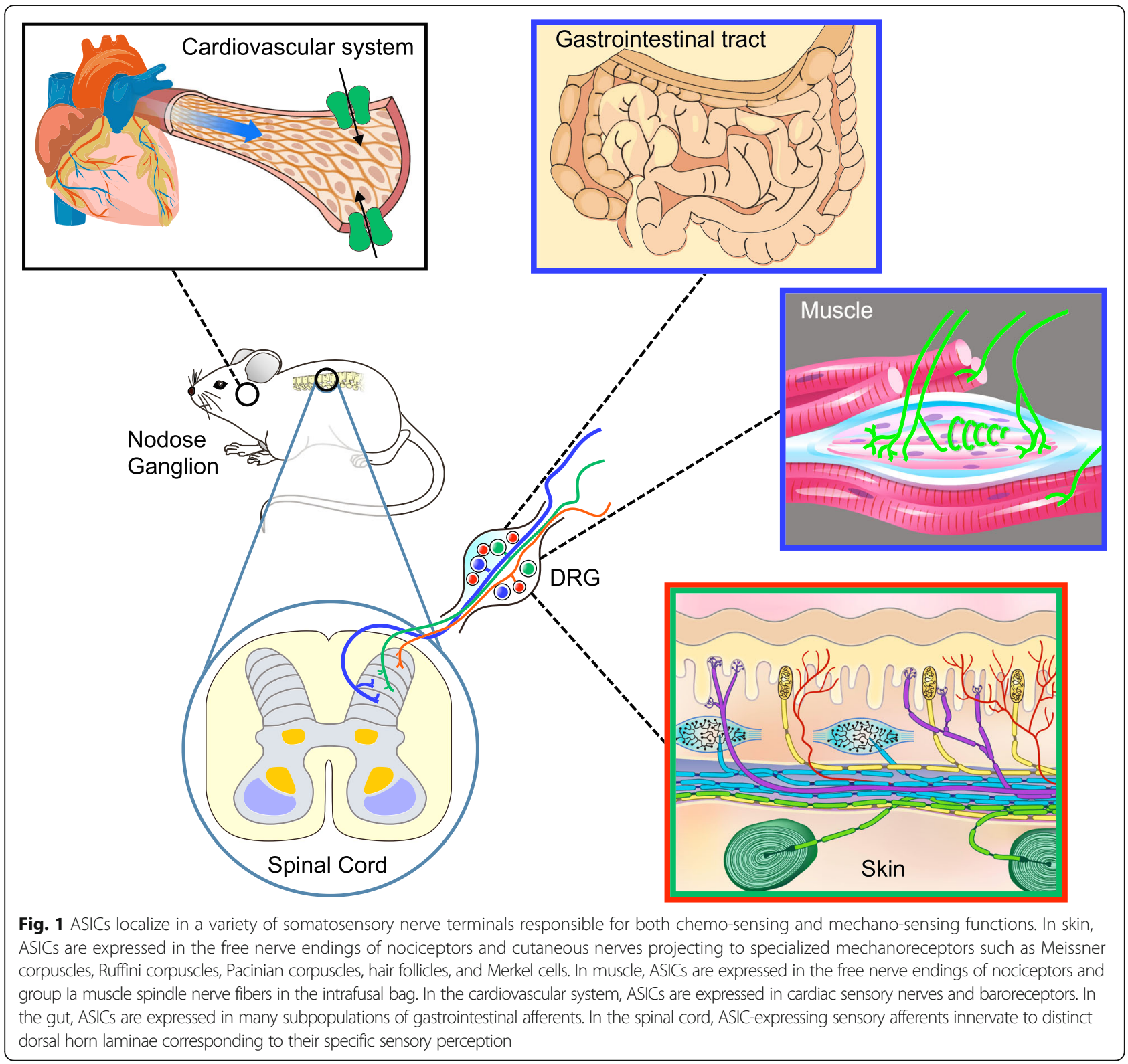


identical ASIC subtypes (homomeric) or a combination of different ASIC subtypes (heteromeric) [13, 14]. Different combinations of ASIC subtypes show different electrophysiology properties. However, the exact ASIC combinations (and ASIC splice variants) in native neurons remain unclear and need further investigation. According to the crystal structure, a hand holding a ball model has been proposed to represent the stereo domain of each subunit [13]. The hand is further divided into an extracellular domain and two transmembrane helixes. A beta-ball surrounded by the finger, thumb, knuckle, and palm, called the acidic pocket, protrudes into the extracellular area to sense the proton and the external stimuli. Two transmembrane helixes insert into a lipid bilayer as the location of the forearm to form the ion channel pore with other subunits.

The expression patterns of each ASIC subtype have been intensively studied with genetic or immunohistochemistry tools in past 2 decades [15] (Table 1). ASIC1a is abundant in the central nervous system (CNS) [16], including most of the brain regions and the spinal cord as well as the peripheral nervous system (PNS) in TG, DRG, NG, and spiral ganglia (SG) [17-19]. With the wide expression profile, ASIC1a has been found involved in modulating neural activity in the brain and detecting noxious acidosis [20]. Besides the nervous system, ASIC1a is also expressed in peripheral tissues including arteries, bone marrow, intestine, tongue, and bladder [21-25]. ASIC1b is specifically expressed in the PNS and involved in pain sensation, but the exact neuron subtypes that express ASIC1b are not well characterized
[26, 27]. ASIC2 (including 2 splice variants, ASIC2a and ASIC2b) is expressed in several brain regions, including the amygdala, hippocampus, cerebellum, olfactory bulb, cortex, brain stem and spinal cord $[28,29]$ as well as in the PNS in DRG [30] and SG [31]. ASIC2 is largely expressed in mechanoreceptors of the somatosensory system [32], such as lanceolate fibers of hair follicles, the Meissner corpuscles, and the Pacinian corpuscles [33] as well as smooth muscles of the aortic arch [34], cerebral artery, and bladder. Thus, much effort has been done to show the involvement of ASIC2 in neurosensory mechanotransduction $[30,34]$. As well, ASIC2 is involved in the pressure-induced smooth muscle contraction [35]. ASIC3 is predominantly expressed in DRG (previously called DRASIC), TG, NG, and SG [3, 36]. In the CNS, ASIC3 is expressed only in the mesencephalic trigeminal nucleus (Me5) neurons in the brain-stem region, which are proprioceptive neurons [37]. Since neurons in DRG are heterogeneous, further molecular identity studies have revealed that ASIC3 is broadly expressed in both peptidergic neurons (expressing CGRP, substance P) [38], non-peptidergic neurons (bound to isolectin B4), pruitoceptors (expressing MRGPRA3), c-mechanoreceptors (expressing tyrosine hydroxylase), myelinated mechanoreceptors (expressing NF-H, TrkC, or NT-3), and proprioceptors (expressing parvalbumin) [3, 15, 39]. Immunohistochemistry studies revealed ASIC3 expression in free nerve endings of the skin and many types of cutaneous nerves projecting to mechanical sensory structures, including lanceolate fibers, Meissner corpuscles, and Merkel cells [38].

Table 1 Expression of ASICs in specific subsets of mechanoreceptors

\begin{tabular}{|c|c|c|c|c|c|c|c|c|}
\hline & ASIC1 & ASIC1a & ASIC1b & ASIC2 & ASIC2a & $A S I C 2 b$ & ASIC3 & ASIC4 \\
\hline Jugular nociceptor & $\begin{array}{l}\text { SC-RT } \\
{[125]}\end{array}$ & $\begin{array}{l}\text { SC-RT } \\
{[125]}\end{array}$ & $\begin{array}{l}\text { SC-RT } \\
{[125]}\end{array}$ & SC-RT [125] & & $\begin{array}{l}\text { SC-RT } \\
{[125]}\end{array}$ & SC-RT [125] & \\
\hline Nodose nociceptor & $\begin{array}{l}\text { SC-RT } \\
{[125]}\end{array}$ & & & SC-RT [125] & $\begin{array}{l}\text { SC-RT } \\
{[125]}\end{array}$ & & SC-RT [125] & $\begin{array}{l}\text { SC-RT } \\
{[125]}\end{array}$ \\
\hline Esophageal mechanoreceptor & $\begin{array}{l}\text { SC-RT } \\
{[125]}\end{array}$ & $\begin{array}{l}\text { SC-RT } \\
{[125]}\end{array}$ & $\begin{array}{l}\text { SC-RT } \\
{[125]}\end{array}$ & SC-RT [125] & $\begin{array}{l}\text { SC-RT } \\
{[125]}\end{array}$ & $\begin{array}{l}\text { SC-RT } \\
{[125]}\end{array}$ & SC-RT [125] & $\begin{array}{l}\text { SC-RT } \\
{[125]}\end{array}$ \\
\hline Muscle spindle & & & SC-RT [40] & IHC [126] & & SC-RT [40] & $\begin{array}{l}\text { IHC [40] } \\
\text { Reporter [40] } \\
\text { SC-RT [40] }\end{array}$ & \\
\hline Hair follicle: Lanceolate complex & & & & $\begin{array}{l}\mathrm{IHC}[30], \mathrm{IHC} \\
{[32]}\end{array}$ & & & $\mathrm{IHC}[38]$ & \\
\hline Hairy skin: Penicillate nerve & & & & $\operatorname{IHC}[32]$ & & & & \\
\hline Meissner's corpscles & & & & $\mathrm{IHC}[32]$ & & & IHC [38] & \\
\hline Merkel cell/neurite complex & & & & $\mathrm{HC}[32]$ & & & $\mathrm{IHC}[38]$ & \\
\hline Cutaneous nociceptor & & & & $\mathbb{I H C}[32]$ & & & IHC [38] & \\
\hline Baroreceptor & $\mathrm{IHC}[34]$ & & & $\mathbb{H C}[34]$ & & & $\begin{array}{l}\mathbb{H C}[34] \mathbb{H C} \\
{[72]}\end{array}$ & \\
\hline $\begin{array}{l}\text { Periodontal ligament Ruffini's } \\
\text { ending }\end{array}$ & & & & & & & $\mathrm{IHC}[36]$ & \\
\hline
\end{tabular}

IHC immunohistochemistry, SC-RT single cell RT-PCR 
However, retrograde tracing studies combined with whole-cell patch clamp recording demonstrate that functional ASIC3 channels are mostly expressed in muscle afferent neurons of DRG nociceptors and proprioceptors $[39,40]$. Besides the nervous system, ASIC3 is also expressed in specific peripheral tissues and cells such as bone marrow [41], intestine, adipose tissues, bladder [22], and joint [42]. However, the functional implication of ASIC3 in these tissues requires further investigation. ASIC4 is mainly expressed in the brain and pituitary gland and in prenatal or neonatal DRG [43, 44]. In the brain, ASIC1a, ASIC2 and ASIC4 are all found in oligodendrocyte-lineage cells $[15,45]$.

\section{Physiological and behavioral phenotyping of ASIC- knockout mice}

The genetic approach has been extensively used to probe the physiological and behavioral phenotypes in mice lacking specific ASIC subtypes and has shed light on the roles of ASICs in chemo-sensing and mechano-sensing functions in the nervous system (Table 2), and the causal role of ASIC deficits in the etiology of neurological disorders (Table 3) [15]. Neuron injury is attenuated in Asicla-knockout $\left(\right.$ Asicla $\left.^{-/-}\right)$mice after ischemic stroke [46], traumatic brain injury [47], and experimental autoimmune encephalitis [48], which suggests a role for ASIC1a in tissue acidosis-induced neuronal excitotoxicity in the brain. Mechanistically, the ASIC1a-mediated calcium conductivity is responsible for neuronal excitotoxicity, which can be inhibited by a selective ASIC1a antagonist PcTx1 [20]. Also, protons are considered potential neurotransmitters activating ASIC1a and thus modulating neural activity and synaptic plasticity in the CNS [49]. Accordingly, Asicla ${ }^{-/-}$mice show impaired neural plasticity in fear circuitry (e.g., amygdala) and reduced fear responses and memory [50]. Of note, amygdala neurons were further found as chemosensors detecting carbon dioxide and acidosis to trigger a fear response [51]. Other related brain behavioral phenotypes of $A_{s i c 1 a^{-1}}$ mice include enhanced cocaine-craving behaviors, elevated amphetamine-induced hyperlocomotion, reduced anxiety-like behaviors [15, 52], and increased chemoconvulsant-induced seizure $[15,53]$. ASIC1a has roles in the PNS in chemo-sensing and

Table 2 Effects of ASICs knockout on neural activity of mechanoreceptors

\begin{tabular}{|c|c|c|c|c|c|}
\hline & ASIC1 KO & $\mathrm{ASIC2} \mathrm{KO}$ & ASIC3 KO & $\mathrm{ASIC} 2 / 3$ & $\mathrm{ASIC} 1 / 2 / 3$ \\
\hline $\begin{array}{l}\text { Nodose arterial } \\
\text { baroreceptor }\end{array}$ & & $\Leftrightarrow[34]$ & & & \\
\hline $\begin{array}{l}\text { Gastroesophageal } \\
\text { mechanoreceptor }\end{array}$ & $\begin{array}{l}\text { Tension receptor } \uparrow[17,127] \\
\text { Mucosal receptor } \uparrow[30]\end{array}$ & $\begin{array}{l}\text { Tension receptor } \downarrow[30] \\
\text { Mucosal receptor } \uparrow[30]\end{array}$ & Tension receptor $\downarrow[30]$ & & \\
\hline $\begin{array}{l}\text { Colonic } \\
\text { mechanoreceptor }\end{array}$ & $\begin{array}{l}\text { Mesentric afferent } \uparrow[30] \\
\text { Serosal afferent } \uparrow[30]\end{array}$ & $\begin{array}{l}\text { Mesentric afferent } \leftrightharpoons[30] \\
\text { Serosal afferent } \uparrow[30]\end{array}$ & $\begin{array}{l}\text { Mesentric afferent } \downarrow[30] \\
\text { Serosal afferent } \downarrow[30] \\
\text { Colonic nociceptor } \downarrow[70]\end{array}$ & & \\
\hline $\begin{array}{l}\text { Cochlear } \\
\text { mechanoreceptor }\end{array}$ & & $\leftrightharpoons[55]$ & & & \\
\hline $\begin{array}{l}\text { Muscle spindle } \\
\text { mechanoreceptor }\end{array}$ & & & $\Leftrightarrow[40]$ & & \\
\hline $\begin{array}{l}\text { Cutaneous RA } \\
\text { mechanoreceptor }\end{array}$ & & $\downarrow[30] \leftrightharpoons[55]$ & $\uparrow[38]$ & & $\leftrightharpoons[77]$ \\
\hline $\begin{array}{l}\text { Cutaneous SA } \\
\text { mechanoreceptor }\end{array}$ & & $\downarrow[30]$ & $\leftrightharpoons[38]$ & & $\leftrightharpoons[77]$ \\
\hline $\begin{array}{l}\text { Cutaneous A-fiber } \\
\text { mechanonociceptor }\end{array}$ & & & $\downarrow[38]$ & & $\uparrow[77]$ \\
\hline $\begin{array}{l}\text { Down-hair } \\
\text { mechanoreceptor }\end{array}$ & & & $\leftrightharpoons[38]$ & & $\leftrightharpoons[77]$ \\
\hline $\begin{array}{l}\text { Cutaneous afferent } \\
\text { C-nociceptor }\end{array}$ & & & $\leftrightharpoons[38]$ & & $\leftrightharpoons[77]$ \\
\hline $\begin{array}{l}\text { DRG-RA MA-current } \\
\text { neurons }\end{array}$ & & $\leftrightharpoons[114]$ & $\leftrightharpoons[114]$ & $\leftrightharpoons[114]$ & \\
\hline $\begin{array}{l}\text { DRG-IA MA-current } \\
\text { neurons }\end{array}$ & & $\leftrightharpoons[114]$ & $\leftrightharpoons[114]$ & $\leftrightharpoons[114]$ & \\
\hline $\begin{array}{l}\text { DRG-SA MA current } \\
\text { neurons }\end{array}$ & & $\leftrightharpoons[114]$ & $\leftrightharpoons[114]$ & $\leftrightharpoons[114]$ & \\
\hline DRG- Proprioceptor & & & $\begin{array}{l}\text { Tether model } \downarrow[40] \\
\text { Bilayer model } \leftrightharpoons[40]\end{array}$ & & \\
\hline
\end{tabular}

IA intermediately adapting, $R A$ rapidly adapting, $S A$ slowly adapting, $M A$ mechanically activated

$\leftrightharpoons$, no change; $\uparrow$, increased activity; $\downarrow$, decreased activity; $\nrightarrow$, impaired or disturbed mechanotransduction 
Table 3 Effects of ASIC-subtype knockout on neurological disorders

\begin{tabular}{|c|c|c|c|c|c|}
\hline & ASIC1a KO & ASIC2 KO & ASIC3 KO & ASIC4 KO & References \\
\hline $\begin{array}{l}\text { Ischemic } \\
\text { stroke }\end{array}$ & $\begin{array}{l}\text { Reduced ischemic brain injury [46]; } \\
\text { Reduced acidosis-induced neuronal } \\
\text { cell death [131] }\end{array}$ & NA & NA & NA & {$[46,131]$} \\
\hline $\begin{array}{l}\text { Learning } \\
\text { and memory }\end{array}$ & $\begin{array}{l}\text { Impaired fear memory [44]; Impaired } \\
\text { spatial memory [133]; No effect on } \\
\text { spatial memory [134] }\end{array}$ & NA & No effect [37] & No effect [44] & {$[37,44,133,134]$} \\
\hline $\begin{array}{l}\text { Multiple } \\
\text { sclerosis }\end{array}$ & $\begin{array}{l}\text { Reduced EAE-induced clinical symptoms } \\
{[48,129,130]}\end{array}$ & $\begin{array}{l}\text { No effects } \\
{[129]}\end{array}$ & No effect [129] & NA & {$[48,129,130]$} \\
\hline Epilepsy & $\begin{array}{l}\text { Impaired seizure termination and increase } \\
\text { kanic acid-induced seizure }[44,53]\end{array}$ & NA & NA & No effect [44] & {$[44,53]$} \\
\hline $\begin{array}{l}\text { Anxiety / Fear } \\
\text { / Depression } \\
\text { /Aggression }\end{array}$ & Reduced fear and anxiety-like behaviors [51] & NA & $\begin{array}{l}\text { Reduced anxiety-like and } \\
\text { aggression-like behaviors; } \\
\text { no effect on depression-like } \\
\text { behaviors [37] }\end{array}$ & $\begin{array}{l}\text { Increased fear } \\
\text { and anxiety-like } \\
\text { behaviors [44] }\end{array}$ & {$[37,44,51]$} \\
\hline Addition & $\begin{array}{l}\text { Increased condition place preference to } \\
\text { cocaine and morphine [52]; Increase } \\
\text { amphetamine-induced hyperlocomotion, } \\
\text { behavioral sensitization, and rewarding [44] }\end{array}$ & $\begin{array}{l}\text { No effect } \\
{[132]}\end{array}$ & NA & No effect [44] & {$[44,52,132]$} \\
\hline $\begin{array}{l}\text { Neuropathic } \\
\text { pain }\end{array}$ & No effect $[128,129]$ & $\begin{array}{l}\text { No effect } \\
{[129]}\end{array}$ & No effect [129] & NA & {$[128,129]$} \\
\hline Fibromyalgia & No effect [61] & NA & No pain developed [61] & NA & [61] \\
\hline $\begin{array}{l}\text { Rheumatic } \\
\text { arthritis }\end{array}$ & Abolished primary hyperalgesia, [42] & NA & $\begin{array}{l}\text { Abolished secondary } \\
\text { hyperalgesia [42] }\end{array}$ & NA & [42] \\
\hline Hearing & NA & $\begin{array}{l}\text { Resistant to } \\
\text { noise-induced } \\
\text { threshold shift [31] }\end{array}$ & $\begin{array}{l}\text { Age-dependent hearing } \\
\text { loss to ultrasound }[74,74]\end{array}$ & NA & {$[74,75]$} \\
\hline
\end{tabular}

NA not available

mechano-sensing. In ex vivo studies, Asicla ${ }^{-/-}$mice show enhanced activity of mechanoreceptors in visceral afferent nerves [17]; in pain behavioral studies, Asicla $^{-/-}$ mice respond to muscle inflammation and develop secondary (or referred) mechanical hyperalgesia in distal tissues but fail to develop primary mechanical hyperalgesia in muscle [54]. Data for $A s i c 1 b^{-/-}$mice are not yet available.

In contrast to $A s i c 1 a^{-/-}$mice, Asic2-knockout $\left(\right.$Asic $\left.^{-/-}\right)$ mice show major deficits in mechano-sensing phenotypes but no obvious chemo-sensing phenotypes [15]. In ex vivo studies, Asic2 ${ }^{-/-}$mice show decreased or disturbed neurosensory mechanotransduction of 2 types of cutaneous afferents (rapidly adapting and slowly adapting low-threshold mechanoreceptors) [30], serosal colonic afferents, and tension and mucosal types of gastroesophageal afferents [17]. At a system level, Asic2 ${ }^{-/-}$ mice show impaired baroreceptor reflex [34], impaired pressured-induced constriction in middle cerebral arteries [35], and resistance to noise-induced threshold shifts in hearing [31]. However some conflicting results challenge a role for ASIC2 in neurosensory mechanotransduction with the use of another Asic2-knockout design [55]. Further studies with subtype-specific Asic $2 a$ and/or Asic $2 b$ models might be helpful to solve the phenotype discrepancy.
Being predominantly expressed in the PNS and the most sensitive proton-sensing ion channel, ASIC3 is proposed to be an important transducer for chemo-sensing, especially for sensing pain associated with tissue acidosis [3]. As well, studies of Asic3-knockout $\left(\mathrm{Asic}^{-/-}\right)$mouse phenotype have shown the involvement of ASIC3 in neurosensory mechanotransduction $[4,56]$. In chemo-sensing, $A s i c 3^{-/-}$mice lost the acid-induced sustained current in DRG neurons that express ASIC-like currents, whereas in wild-type mice, $\sim 20 \%$ of DRG neurons expressed ASIC3-like currents containing the sustained component [57]. Accordingly, $A s i c 3^{-/-}$mice show largely reduced acid-induced pain behaviors [58, 59] and impaired triggering of acid-induced nociceptor priming [60]. In a mouse model of fibromyalgia, $A s i c 3^{-/-}$mice failed to develop chronic widespread muscle pain induced by repeated intramuscular injections of acid saline [60-62]. Also, $A s i c 3^{-/-}$mice show impaired triggering of pain associated with tissue acidosis under the conditions of surgery, cardiac ischemia, muscle and joint inflammation, and rheumatoid arthritis [42, 54, 63-67]. In mechano-sensing, $\mathrm{Asic3}^{-/-}$mice show abnormal neurosensory mechanotransduction of cutaneous and visceral afferents in ex vivo studies of electrophysiological recordings on tissue-nerve preparations [4]. In skin, $A s i c 3^{-/-}$mice show increased activity of rapidly adapting mechanoreceptors and decreased 
activity of A-fiber mechanoreceptors, so the mice might be more sensitive to light touch and less sensitive to a noxious pinch than wild-type mice [38]. However, inconsistent with the ex vivo studies, $A s i c 3^{-/-}$mice show hypersensitive nocifensive behaviors to dynamic mechanical stimuli [68] and noxious mechanical pressure on the tail [69]. In the viscera, $A s i c 3^{-/-}$mice show decreased activity of tension gastroesophageal afferents and decreased serosal and mesenteric colonic afferents, which suggests that ASIC3 might play a role in visceral nociception $[17,70,71]$. At the system level, ASIC3 is involved in neurosensory mechanotransduction of low-threshold baroreceptors, proprioceptors, skin nociceptors, and the cochlear; indeed, $\mathrm{Asic}^{-/-}$mice show deficits in blood volume expansion-induced diuresis [72], proprioceptive behaviors while walking on a balance beam [40], pressure-induced vasodilatation in skin [73], and age-dependent hearing loss [74, 75].

The role of ASIC4 in chemo-sensing and mechano-sensing is still questioned, because ASIC4 itself does not form a functional channel [43]. ASIC4 can downregulate the surface expression of ASIC1a and ASIC3 and thus reduce the acid-induced current of ASICs [76]. Consistently, Asic4-knockout $\left(\right.$ Asic $\left.^{-/-}\right)$mice have shown contrasting behavioral phenotypes to ASIC1a in modulating innate fear and anxiety [44].

These results indicate that ASICs play an important role in chemo-sensing and mechano-sensing in the somatosensory system. Intriguingly, sometimes an ASIC subtype knockout does not downregulate mechano-sensing phenotypes but rather results in enhanced neural activity of cutaneous and/or visceral mechanoreceptors as well as hypersensitive pain responses to noxious stimuli [4]. Also, inconsistent results are found between in vitro, ex vivo, and in vivo assays. For instance, in $\mathrm{Asic}^{-/-}$mice, the hypersensitive nocifensive behaviors to noxious mechanical stimuli do not match the reduced activity of A-fiber mechanoreceptors in ex vivo study. Moreover, although A-fiber mechanoreceptor activity is reduced in $\mathrm{Asic3}^{-/-}$mice and not altered in $\mathrm{Asicla}^{-/-}$or Asic2 $2^{-/-}$mice, the Asic1a ${ }^{-/-}:: A s i c 2^{-/-}::$Asic3 $^{-/-}$triple knockout results in increased activity of A-fiber mechanoreceptors [77]. Gene redundancy is usually used to explain the unexpected results found in a single gene knockout study, if the knockout gene belongs to a gene family containing other functional homologs. However, the ASIC triple knockout results almost deny the possible gene redundancy, unless there are more functionally active proteins inside the ASIC channel complex playing roles. Alternatively, there might be technical limitations in current approaches to probe the neurosensory mechanotransduction in vitro, ex vivo, or in vivo. One important issue is to know the proper channel-gating model we are investigating when the assays are designed to probe the neurosensory mechanotransduction.

\section{Molecular basis of chemo-sensing in ASICs}

Regarding chemo-sensing, ASICs can respond to an external acidic-environment decrease from $\mathrm{pH} 7.4$ to a modest level ( $\mathrm{pH}$ 6.8) or even harsh acidosis $(\mathrm{pH} 4.0)$ [20]. The pH sensitivity of ASIC subtypes is in the order of ASIC3 $\geq$ ASIC1a $>$ ASIC1b > ASIC2a. Neither ASIC2b nor ASIC4 respond to acidification, but they form functional channels with other ASIC subtypes and thus modulate their $\mathrm{pH}$ sensitivity and channel properties. The activation of ASICs induces an inward current to depolarize neurons [78]. From the ASIC1a crystalize structure, an acidic pocket containing several pairs of acidic amino acids has been proposed to be one of the $\mathrm{pH}$-sensors of ASIC channels located at the interface between two subunits, whereas cations may access the channel from the lateral wrist region, then move into a broad extracellular vestibule and reach the channel pore region [79] (Fig. 2a). When ASICs are activated, the inward current desensitizes rapidly, except for ASIC3, which mediates both a rapidly desensitized current and an un-inactivated sustained current during the acidic challenge period (Fig. 2b). The sustained ASIC3 current results from the window of overlap between inactivation and activation of the transient component, which means the sustained current is a result of steady state desensitization. The sustained component of ASIC3 is important for the perception of primary inflammatory pain $[58,80]$. The regulation of steady-state desensitization could be further analyzed by fitting the Polymodal Monod-Wyman-Changeux Model with its dose-response curve, by which the slope (Hill coefficient) of the dose-response curve for one stimulus can be pursued to define the intrinsic property of a channel [81]. While the transmembrane domain 1 of ASIC3 and ASIC1a is swapped, the ASIC1a/ASIC3 chimera did not change the Hill coefficient or the $\mathrm{pH}_{50}$ of the activation of ASIC1a but strongly promoted the sustained current by stabilizing the open state of channels [82]. Further studies of ASIC1a have revealed that the extracellular linker regions and acidic residues in the acidic pocket are not essential for channel activation but affect the desensitization kinetics and thus control the sustained current. These mechanistic insights could provide opportunities for fine-tuning the $\mathrm{pH}$ dependence of ASICs [83, 84].

Besides the structure-activity relationship, pharmacology studies have largely advanced our understanding of chemo-sensing of ASICs [12]. For instance, amiloride is a pan-ASIC reversible blocker inhibiting only the transient current but not the sustained component. However, 

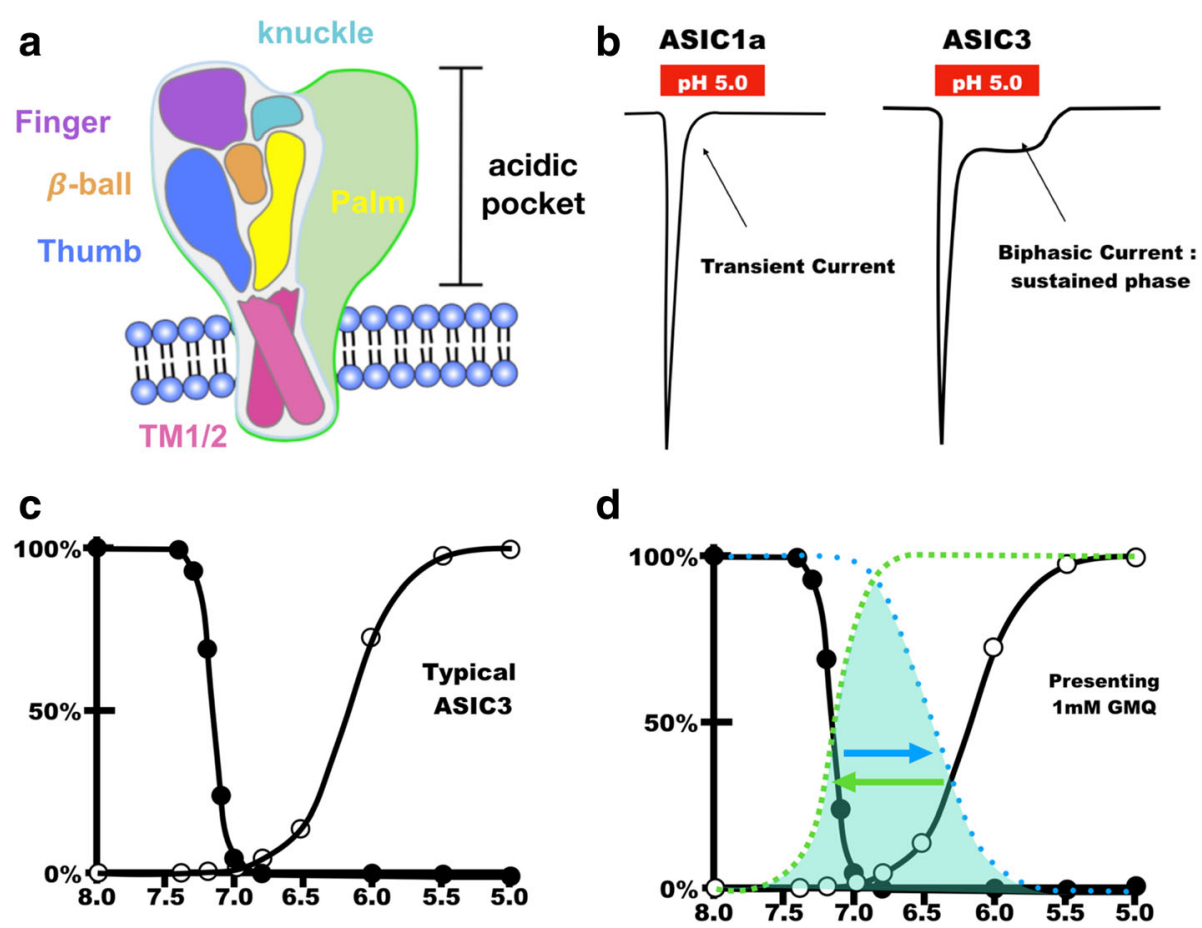

Fig. 2 The structure and function of ASICS. a A trimeric ASIC channel comprises three subunits. Each subunit constructs "a hand holding a ball" structure to sense the extracellular proton and regulate the proton-gated currents. There are three major categories of non-proton regulators (synthetic/nature compound, endogenous metabolites, and divalent cations) to activate or modulate ASICs in a conformational change of structure. $\mathbf{b}$ The ASIC1a (or ASIC1b, ASIC2a) homomeric channel mediates a transient current, whereas the ASIC3 homomeric channel mediates a biphasic current containing a transient component followed by a non-inactivated sustained component. c, $\mathbf{d}$ The non-proton regulators (e.g., $1 \mathrm{mM} \mathrm{GMQ}$ ) may shift the activation (open circle) or inactivation (filled circle) curve by changing the conformation of ASIC channels and enhance the window current (the shadow region underneath the dotted lines)

paradoxical results have shown that high concentrations of amiloride are able to open the homomeric ASIC3 channels or heteromeric ASIC3/ASIC1b channels at neutral $\mathrm{pH}$ and mediate a sustained current, synergistically enhancing the channel activation induced by acidosis $[10,85]$. More recently, a small synthetic molecule, 2-guanidine-4-methylquinazoline (GMQ), was found to activate and modulate the ASIC3 channel at neutral $\mathrm{pH}$ by affecting the desensitization [86]. Besides the synthetic compounds, ASICs are also sensitive to divalent cations. For instance, the neurotoxic metal ion $\mathrm{Pb}^{2+}$ reversibly and dose-dependently inhibits ASIC currents in neurons of the PNS and CNS [87]. ASIC1a, ASIC1b, and ASIC3 subtypes are all sensitive to $\mathrm{Pb}^{2+}$ inhibition via the binding of the extracellular loop, which is independent of amiloride $/ \mathrm{Ca}^{2+}$ blockade.

As mentioned previously, ASICs can be activated by synthetic compounds such as aimloride and GMQ at neutral $\mathrm{pH}$. The non-acid chemo-sensing property of ASICs is further established by the identification of endogenous ligands from inflammatory mediators. Arachidonic acid and lysophosphatidylcholine (16:0), the metabolites of phospholipids, activate ASIC3 at neutral pH [88]. Both arachidonic acid and lysophosphatidylcholine
(16:0) can potentiate an ASIC current by shifting the ASIC3 activation state close to physiological pH 7.4 and increase the window current [89]. Recent studies also identified the endogenous isoquinoline alkaloids, the precursors of endogenous morphine biosynthesis, as the non-proton ligands of ASIC3 [90]. Moreover, alkaloid lindoldhamine isolated from Laurus nobilis is another non-proton ligand of ASIC3 opening the channel under neutral or even more alkaline ( $\mathrm{pH}>7.4$ ) conditions [91].

One of the most important chemo-sensing properties of ASICs is probably the sensing of lactate. Anaerobic metabolism occurring during tissue ischemia and/or fatiguing exercise results in an accumulation of lactates (up to $15 \sim 50 \mathrm{mM}$ ) and local or systemic lactic acidosis [92]. In the presence of $15 \mathrm{mM}$ lactate, acid ( $\mathrm{pH}$ 7.0)-induced ASIC-like currents increase about $70 \%$ in cardiac ischemia-sensing DRG neurons [93]. Lactate dose-dependently enhances ASIC1a and ASIC3 activity via chelating extracellular divalent cations such as $\mathrm{Ca}^{2+}$ or $\mathrm{Mg}^{2+}$. Moreover, lactate specifically enhances the sustained ASIC3 current at $\mathrm{pH} 7.1 \sim 7.2$ but not $\mathrm{pH} 7.0$ and below [94]. The lactate modulation can work on ASICs in excised membrane patches, which suggests that the process does not involve a separate receptor or 
signaling cascade. Lactic acid is among several compounds triggering angina chest pain or ischemic muscle pain. In ischemic pain, lactate modulation is an example of heterosensitization, in which a stimulus (lactate) increases nociceptor sensitivity without directly activating the transducer (ASICs on ischemia-sensing neurons). Accordingly, homomeric ASIC3 (in rats) and heteromeric ASIC2/ASIC3 (in mice) are the major chemo-sensing transducers in cardiac ischemia-sensing afferent neurons $[95,96]$.

Together, the activation and desensitization of ASICs involve a variety of responses with excellence flexibility to present the environmental change without changing the channel itself (Fig. 2c,d).

\section{Mechano-sensing mechanism of ASICs}

Although accumulating evidence from genetic studies has suggested that ASICs are mechanical transducers involved in neurosensory mechanotransduction, the mechanical gating mechanism of ASICs is still unclear [4]. The Nobel laureate Martin Chalfie proposed a MEC-4/MEC-10 model (or "tether model") to describe the molecular mechanism of the mechano-sensing apparatus and the putative gating mechanism in Caenorhabditis elegans touch receptor neurons (TRNs) [97]. Genetic screening of mechanosensory abnormality (mec) mutants in the nematode revealed a series of mec genes that encode proteins involved in the mechano-sensing apparatus of TRNs. The TRN mec-encoding proteins include mechanically activated ion channels, extracellular matrix proteins, cytoskeleton, and accessory proteins. Accordingly, the mechanically activated ion channel MEC-4 was first discovered in 1981, and later MEC-10 was found, both of which are the nematode homologs of ASICs [98], belonging to the DEG/ENaC family $[99,100]$. To transduce the mechanosensation of TRNs, MEC-4 and MEC-10 proteins need to collaborate with other force-transmitting molecules such as extracellular matrix, cytoskeleton, and accessory proteins. The extracellular matrix proteins include MEC-1 and MEC-9 (proteins containing multiple kunitz and epidermal growth factor-like domains), and MEC-5 (collagen-like protein), which are proposed to receive mechanical stimulus and transfer the force to the tethered, mechanically activated ion channels. The cytoskeleton proteins MEC-7 ( $\alpha$-tubulin) and MEC-12 ( $\beta$-tubulin) can form protofilament microtubules that are important for force transmission and they maintain specialized structures of mechanosensory puncta. These elastic bundles of extracellular matrix and cytoskeleton proteins may directly or indirectly link with the mechanically activated ion channels MEC-4/MEC-10 to propagate the force and activate the channels. Furthermore, many accessory proteins such as MEC-2 (stomatin-like protein containing a prohibitin domain) and MEC-6 (paraoxonase-like protein) are essential for full functionality of touch sensation in nematodes. The central stomatin-like domain of MEC-2 is predominantly palmitoylated and associated with lipid rafts. Notably MEC-2 provides an important structural scaffold for interaction between MEC-4/MEC-10 proteins and the surrounding lipids to work as a gating-spring for mechanotransduction. Together, these accessory MEC proteins involved in the mechano-sensing apparatus can directly or indirectly tether to the mechanically activated ion channels (MEC-4/MEC-10) and thus deliver the mechanical stimulus from the external environment to open the channels. The gating mechanism of the mechano-sensing apparatus is thus named the "tether model", which emphasizes the extracellular and cytoplasmic tethers acting like a gating-spring to transmit the stimulus force to the channels $[97,98,101]$.

As homologs of MEC-4/MEC-10 in mammals, ASICs interact with stomatin-domain proteins, including stomatin, stomatin-like 1 (STOML1), and somatin-like 3 (STOML3) [56, 102, 103]. These stomatin-domain proteins have different inhibitory effects on acid-induced currents of ASIC1a, ASIC2a, and ASIC3. Especially, STOML3 inhibits acid-induced currents of ASIC2a and ASIC3, and in Stoml3-knockout mice, $\sim 40 \%$ of skin mechanoreceptors are insensitive to mechanical stimuli [104]. Accordingly, Stoml3-knockout mice fail to develop mechanical allodynia after neuropathic injury. In mammals, PDZ-domain proteins are required for surface expression of ASICs in neurons. For instance, protein interacting with $\mathrm{C}$ kinase 1 (PICK1) modulates the surface expression of ASIC1a, ASIC2a, and ASIC3 in mechanosensory DRG neurons [105-108], whereas Lin-7b and CIPP increase the surface expression of ASIC3 and acid-induced ASIC3 [106, 109]. These PDZ-domain proteins may act as a membrane scaffold via lipid binding to enhance the surface clustering of ASICs and regulate the channel activity. Although they are important for ASIC surface expression, their roles in modulating neurosensory mechanotransduction have yet to be proved. Another PDZ-domain protein, whirlin, is expressed in proprioceptors, a type of low-threshold mechanoreceptor. Mice lacking whirlin show impaired neurosensory mechanotransduction of proprioceptors [110], but the interaction between whirlin and ASICs is not known.

In addition to the MEC-4/MEC-10 model, Lin et al. showed that extracellular matrix and cytoskeleton proteins are essential for mechanotransduction of the tether model in cultured mouse DRG neurons [111]. Moreover, the involvement of extracellular matrix proteins in neurosensory mechanotransduction of mammals is due to 
RGD ligands targeting on integrins (e.g., collagen; laminin-111, - 211, - 511, and - 332; fibronectin) being able to modulate the mechanically activated responses in the mammalian skin-nerve recording or acute dissociated DRG neurons $[112,113]$. However, the direct interaction between RGD-containing extracellular matrix proteins and ASICs requires further investigation.

Molecules involved in the tether model of mechanotransduction seem conserved in sensory neurons from nematodes to mammals (Fig. 3). However, although ASICs play an important role in neurosensory mechanotransduction, proving their direct participation in the transduction event like MEC-4/MEC-10 is challenging. In 2004, Drew et al. reported no effects on mechanically activated currents in $\mathrm{Asic2}^{-/-}, \mathrm{Asic}^{-/-}$, and $\mathrm{Asic2^{-/- }}:: \mathrm{Asic}^{-/-}$ mice as compared with wild-type littermates in all different DRG neuron populations [114]. Therefore, lack of direct evidence to support ASICs as the mechanically activated channels is a concern in this field. Martin Chalfie raised several challenging issues in discovering a mechanically activated ion channel in eukaryotic organisms, especially in mammals. First, the sensory cells or their receptor endings are sparse, so targeting the mechanical sensors and collecting sufficient number of cells for biochemical assay is difficult. Second, an extremely low amount of the receptor is found. Finally, and perhaps most importantly, assaying the function of candidate transduction molecules in heterologous systems can be difficult. For instance, changing the osmotic pressure of solution can manipulate the membrane tension and is used to identify mechanically activated ion channels (e.g., MscL and MscS of bacteria) that sense forces conveyed through the lipid bilayer [115]. This type of gating mechanism is named the "bilayer model", which transduces a stimulus modality different from the gating mechanism of the tether model that opens MEC-4/MEC-10 or ASICs via a gating-spring. Another common approach to assay mechanotransduction of the bilayer model in eukaryotic cells (or neurons) is to directly

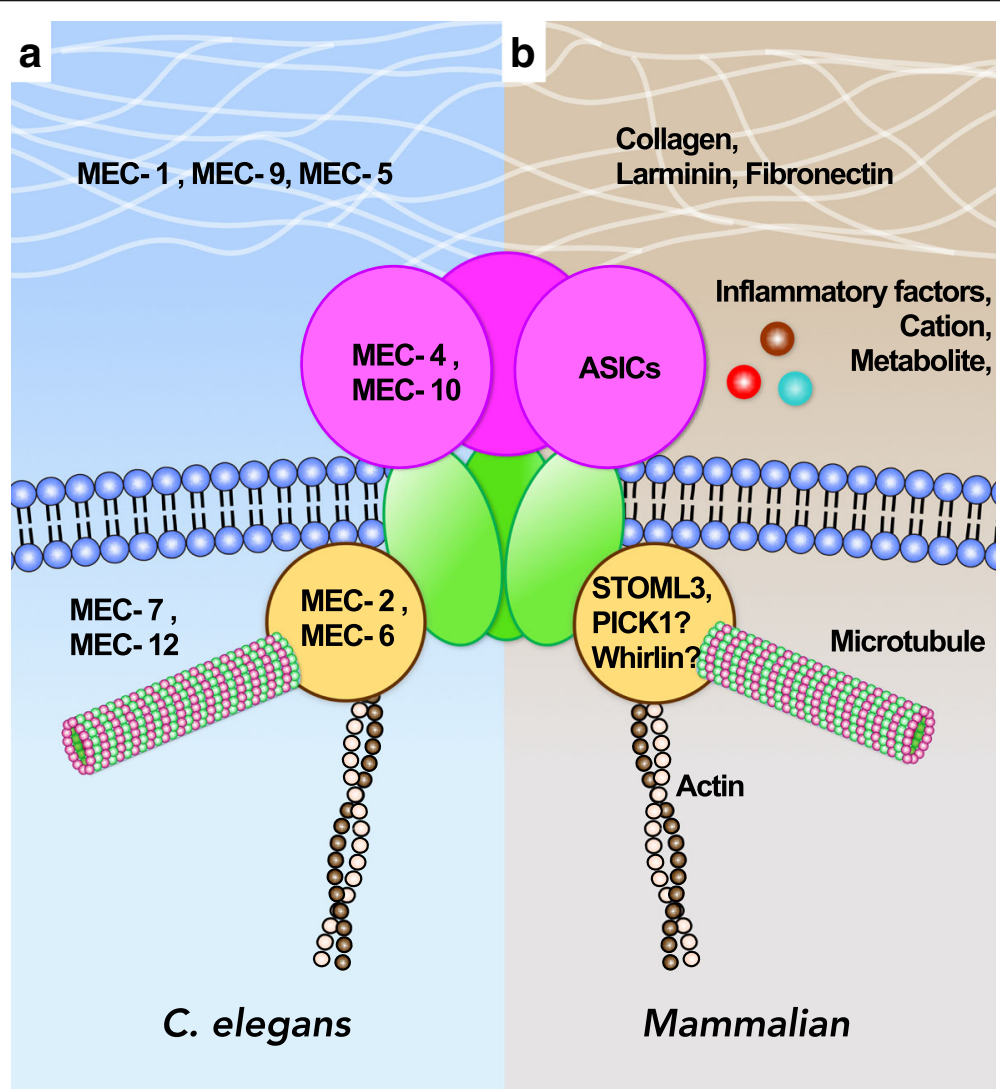

Fig. 3 The molecular apparatus that mediates the "tether model" mechanotransduction is conserved between nematodes and mammals. a Caenorhabditis elegans has many mechanosensory abnormality (mec) mutant genes involved in the tether-model mechanotransduction responsible for gentle touch. These mec gene products are MEC-4 and MEC-10 (DEG/ENaC channels), MEC-2 and MEC-6 (channel-associated proteins), MEC-7 and MEC-12 (protofilament microtubules), and MEC-1, MEC-5, and MEC-9 (extracellular matrix proteins). These proteins illustrate a tethering gating model of mechanically activated ion channels in nematodes. $\mathbf{b}$ In mammals, ASICs are homologs of MEC-4 and MEC-10 and are also involved in the tether model of mechanotransduction. ASICs interact with channel-associated proteins PICK1 and STOML3 (and possibly whirlin) and could be regulated by extracellular matrix proteins (e.g., collagen, laminin, and fibronectin) or cytoskeleton proteins such as actin and microtubules 
indent the cell surface membrane by using a blunt pipette (mechano-clamp) or pressure jet/suction force to the cell surface (fast-step pressure clamp) [116]. As mentioned previously, Drew and colleagues (in 2004) used the mechano-clamp approach to discount a role for ASICs in this mechanical gating mechanism of the bilayer model. Examining the role of ASICs in mechanotransduction requires assaying the tethered mechanically activated ion channels in vitro, which had not been developed until 2009 [117].

To conquer the limitation of the mammalian nerve system heterogeneity and the challenge of identifying mechanically activated ion channels in eukaryotic organisms, we have successfully developed a novel system to probe localized neural mechanotransduction by using surface-modified elastomeric matrices and electrophysiology, with which we can simultaneously examine the acid-sensing responses and mechanotransduction of the tether and bilayer models in the same cells (Fig. 4) [118]. In this system, we can stretch a single neurite via substrate deformation without contacting the neuron surface to mimic the tethering mechanotransduction of TRN in the nematodes. We thus integrated this elastomeric matrix system and whole-cell patch-clamp recording with ASIC3 conditional knockout and GFP-reporter mice driven by pavalbumin-Cre (representing proprioceptors in the mouse somatosensory system) [40]. We could thus identify ASIC3-expressing DRG proprioceptors via fluorescent microscopy and conduct patch-clamp recording to assay the electrophysiological responses of acid-sensing and mechano-sensing in the same cells. We found that ASIC3 is a functional channel for the acid-induced current in all DRG proprioceptors, although these neurons are known as low-threshold mechanoreceptors. The substrate deformation-driven neurite stretch triggers an action potential or inward current in most DRG proprioceptors, which are largely abolished in mice lacking ASIC3. The result indicates ASIC3 involved in the tether-model mechanotransduction of DRG proprioceptors. However, in $A s i c 3^{-/-}$DRG proprioceptors, direct neurite indentation by using a blunt pipette induces an action potential similar to $\mathrm{Asic}^{+/+}$DRG proprioceptors, which suggests that the bilayer model mechanotransduction is still intact. This is the first example with which we can clearly determine a role for ASIC3 directly participating in mechanotransduction in an in vitro assay system. Echoing the MEC-4/MEC-10 model in nematodes, ASIC3-mediated mechanotransduction is specific for the tether but not bilayer model. Moreover, ASIC3 seems to be a dual-function protein in proprioceptors exerting both acid-sensing and mechano-sensing functions. Whether other ASIC subtypes play a role similar to ASIC3 are unknown but remain for further investigation.

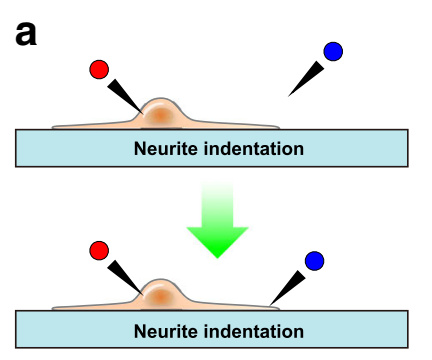

b

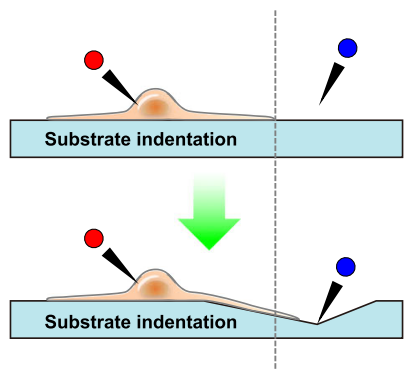

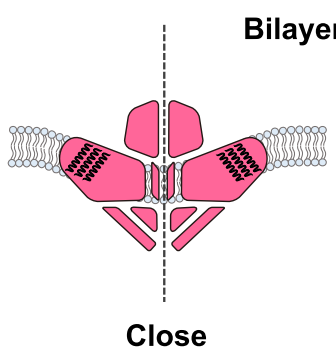

Tether model
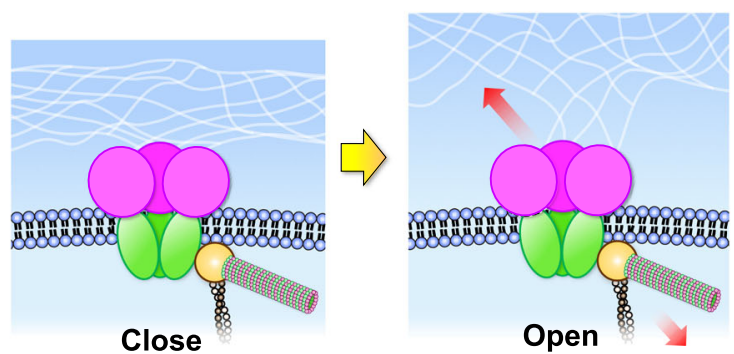

Fig. 4 Approaches and mechano-gating mechanisms of the "bilayer model" and "tether model" of mechanically activated ion channels. a Direct neurite indentation by using a blunt pipette alters membrane tension and thus opens the mechanically activated ion channel of the bilayer model (e.g., PIEZO2). b Substrate deformation-driven neurite stretch acts on channel-tethering proteins of the extracellular matrix and cytoskeletons and thus opens the mechanically activated ion channels of the tether model (e.g., MEC-4/MEC-10 or ASICs) 


\section{ASICs as tunable somato-sensory transducers}

Cells dynamically interact with changes in surroundings by various mechanisms (including chemo-sensing, mechano-sensing, and thermo-sensing) in different timescales. Neurosensory mechanotransduction is extremely fast and too rapid to involve a chemical intermediate, so the electrical response must result from the direct gating of a transduction channel. The discovery of PIEZO proteins as the mechanically activated ion channels of the bilayer model is a milestone in mechanobiology [116]. PIEZO channels fulfill most of the requirements for the true mechanically activated ion channels and were soon found to play important roles in neurosensory mechanotransduction, including proprioception, sensing light touch, and sensing stretch in organs (e.g., lung) [118]. However, PIEZO proteins lack the chemo-sensing function, and their capacity to respond to environmental changes is limited. PIEZO2-mediated mechanically activated currents can be enhanced by STOML3 [119] or GPCR receptor signaling mediated by bradykinin [120], but no chemical mediators have been found to modulate PIEZO protein activity directly. The gating mechanism of PIEZO channels follows the bilayer model, with the mechanical force directly transmitted to the channel via lateral tension in the membrane bilayer. This gating mechanism is firm and rigid and is little tunable by environmental changes.

In contrast, MEC-4/MEC-10 or ASICs are more tunable transducers than PIEZO proteins in response to various somatosensory stimuli. In nematodes, although MEC-4 is the major component of the conductive ion channel, MEC-10 still plays a regulatory role in the mechanical sensing complex [121]. In mammals, ASIC3 is a major component responsible for tether-model mechanotransduction in DRG proprioceptors [40]. ASIC3-containing channels are heterogeneous and could be assembled as an ASIC3 homomeric or heteromeric trimer with ASIC1a, ASIC1b, ASIC2a, or ASIC2b, with distinguishable channel kinetics and modulated by different chemical mediators. Thus, ASICs may work as a tunable unit in parallel to PIEZO2 in neurosensory mechanotransduction in mammals. For instance, PIEZO2 plays a major role in mechanotransduction of low-threshold mechanoreceptors for proprioception and sensing light touch, whereas ASICs show indispensable functionality in regulating mechanotransduction in the same sensory neurons [40,122-124]. As discussed previously, the channel kinetics of ASICs in chemo-sensing could be altered by many endogenous environmental changes, including acidosis, metabolites, extracellular cations, cytokines and inflammatory factors, and thus reveal ASICs as important transducers of peripheral sensitization in the somatosensory nervous system. Whether these environmental factors could modulate the mechanically gating property of ASICs is intriguing and requires further investigation. In addition, as a channel for tether-model mechanotransduction, mechanical strikes by the extracellular matrix, membrane-associated protein, and cytoskeleton could further fine-tune the already tunable ASICs and provide excellent flexibility for mechanotransduction in mammals.

\section{Conclusions}

In conclusion, we are just beginning to appreciate the tunable function of ASICs and the dual-function roles of ASIC3 in chemo-sensing and mechano-sensing. Still, several basic questions about the roles of ASICs in mechano-sensing functions remain unsolved. First, we are yet to reproduce the ASIC-mediated mechanically activated current in a heterologous expression system. To reproduce the mechanosensitivity of ASICs in non-neuronal cells could be challenging, because the tether-model mechanotransdution can be only assessed in a neurite-like structure and the mechanotransducer might be a complex of the transducer channel and many accessory proteins, plus specific ECM components. Much effort is needed to identify the important molecules involved in the mechanotransducer complex. Second, we are yet to know the roles of each ASIC subtype and the heteromeric ASIC channels in mechano-sensing and related biological functions, such as the modulation of mechanical sensitivity by endogenous metabolites or the other extracellular ligands. Furthermore, the exact combination of ASIC subtypes for an endogenous ASIC channel is not clear. Finally, it is still not known whether the mechano-sensing function of ASICs is involved in neurological disorders beyond proprioception, especially in the central nervous system. For instance, in the context of stroke, both acid-sensing and mechano-sensing functions of ASICs might play roles in response to ischemia and increased intracranial pressure. However, as shown in the Table 3, most neurological disorders seem to be related to the acid-sensing function of ASICs. Future research on each ASIC subtype will continue to pave the way to a better understanding of our somatosensory system and its importance in regulating biological processes in response to external and internal challenges.

\footnotetext{
Abbreviations

ASIC3: Acid-sensing ion channel 3; Asic $3^{-1-}$ : Acid-sensing ion channel 3 knockout; ASICs: Acid-sensing ion channels; CNS: Central nervous system; DEG/ENaC: Degenerin/epithelium sodium channel; DRG: Dorsal root ganglia; mec: Mechanosensory abnormality; NG: Nodose ganglia; PNS: Peripheral nervous system; SG: Spiral ganglia; STOML1: Stomatin-like 1;

STOML3: Stomatin-like 3; TG: Trigeminal ganglia; TRN: Touch receptor neuron
}

\section{Acknowledgements}

We thank the staff of the IBMS medical art room for their wonderful work in scientific illustration. 


\section{Funding}

This work was supported by intramural funding of Academia Sinica and grants from the Ministry of Science and Technology, Taiwan (MOST 105-2320-B-001018-MY3, MOST106-2321-B-001-044, and MOST 106-2319-B-001-004). YRC was supported by the Dei-Mei Brain Tumor Education Foundation.

\section{Authors' contributions}

CCC composed the idea and wrote the manuscript. YRC was involved in drafting the manuscript and preparing the figure illustration. BYJ was involved in preparing the information in the tables. All authors read and approved the final manuscript.

\section{Ethics approval and consent to participate}

Not applicable.

\section{Competing interests}

The authors declare that they have no competing interests.

\section{Publisher's Note}

Springer Nature remains neutral with regard to jurisdictional claims in published maps and institutional affiliations.

\section{Author details}

'Department of Life Science, National Taiwan University, Taipei 106, Taiwan. ${ }^{2}$ Institute of Biomedical Sciences, Academia Sinica, 128, Academia Rd. Sec. 2 Taipei 115, Taiwan. ${ }^{3}$ Taiwan Mouse Clinic - National Comprehensive Mouse Phenotyping and Drug Testing Center, Academia Sinica, Taipei 115, Taiwan.

\section{Received: 24 January 2018 Accepted: 15 May 2018}

Published online: 24 May 2018

\section{References}

1. Katta S, Krieg M, Goodman MB. Feeling force: physical and physiological principles enabling sensory mechanotransduction. Annu Rev Cell Dev Biol. 2015;31:347-71

2. Levin LR, Buck J. Physiological roles of acid-base sensors. Annu Rev Physiol. 2015;77:347-62

3. Wu WL, et al. Targeting ASIC3 for pain, anxiety, and insulin resistance. Pharmacol Ther. 2012;134(2):127-38.

4. Chen CC, Wong CW. Neurosensory mechanotransduction through acidsensing ion channels. J Cell Mol Med. 2013;17(3):337-49.

5. Dubin AE, Patapoutian A. Nociceptors: the sensors of the pain pathway. J Clin Invest. 2010;120(11):3760-72.

6. Birdsong WT, et al. Sensing muscle ischemia: coincident detection of acid and ATP via interplay of two ion channels. Neuron. 2010;68(4):739-49.

7. Sun $\mathrm{WH}$, Chen CC. Roles of proton-sensing receptors in the transition from acute to chronic pain. J Dent Res. 2016;95(2):135-42.

8. Ranade SS, Syeda R, Patapoutian A. Mechanically activated ion channels. Neuron. 2015:87(6):1162-79.

9. Hong $\mathrm{K}$, et al. Mechanical activation of angiotensin II type 1 receptors causes actin remodelling and myogenic responsiveness in skeletal muscle arterioles. J Physiol. 2016;594(23):7027-47.

10. Waldmann $R$, et al. A proton-gated cation channel involved in acid-sensing. Nature. 1997:386(6621):173-7.

11. Baron A, et al. Venom toxins in the exploration of molecular, physiological and pathophysiological functions of acid-sensing ion channels. Toxicon. 2013;75:187-204

12. Baron A, Lingueglia E. Pharmacology of acid-sensing ion channels physiological and therapeutical perspectives. Neuropharmacology. 2015;94 19-35.

13. Jasti J, et al. Structure of acid-sensing ion channel 1 at 1.9 a resolution and low pH. Nature. 2007;449(7160):316-23.

14. Noel J, et al. Current perspectives on acid-sensing ion channels: new advances and therapeutic implications. Expert Rev Clin Pharmacol. 2010;3(3): $331-46$

15. Lin SH, Sun WH, Chen CC. Genetic exploration of the role of acid-sensing ion channels. Neuropharmacology. 2015;94:99-118.

16. Price MP, et al. Localization and behaviors in null mice suggest that ASIC1 and ASIC2 modulate responses to aversive stimuli. Genes Brain Behav. 2014; 13(2):179-94.
17. Page AJ, et al. Different contributions of ASIC channels 1a, 2, and 3 in gastrointestinal mechanosensory function. Gut. 2005:54(10):1408-15.

18. Ugawa $\mathrm{S}$, et al. Acid-sensing ion channel-1b in the stereocilia of mammalian cochlear hair cells. Neuroreport. 2006;17(12):1235-9.

19. Hughes PA, et al. Localization and comparative analysis of acid-sensing ion channel (ASIC1, 2, and 3) mRNA expression in mouse colonic sensory neurons within thoracolumbar dorsal root ganglia. J Comp Neurol. 2007; 500(5):863-75.

20. Wemmie JA, Taugher RJ, Kreple CJ. Acid-sensing ion channels in pain and disease. Nat Rev Neurosci. 2013;14(7):461-71.

21. Richter TA, et al. Acid-sensing ion channel-2 is not necessary for sour taste in mice. J Neurosci. 2004;24(16):4088-91.

22. Kobayashi $\mathrm{H}_{\text {, et }}$ al. Sex differences in the expression profile of acid-sensing ion channels in the mouse urinary bladder: a possible involvement in irritative bladder symptoms. BJU Int. 2009:104(11):1746-51.

23. Chung WS, et al. Extracellular acidosis activates ASIC-like channels in freshly isolated cerebral artery smooth muscle cells. Am J Physiol Cell Physiol. 2010;298(5):C1198-208.

24. Dong $X$, et al. Expression of acid-sensing ion channels in intestinal epithelial cells and their role in the regulation of duodenal mucosal bicarbonate secretion. Acta Physiol (Oxf). 2011:201(1):97-107.

25. Swain SM, et al. Proton-gated ion channels in mouse bone marrow stromal cells. Stem Cell Res. 2012;9(2):59-68.

26. Chen CC, et al. A sensory neuron-specific, proton-gated ion channel. Proc Natl Acad Sci U S A. 1998;95(17):10240-5.

27. Diochot $\mathrm{S}$, et al. Black mamba venom peptides target acid-sensing ion channels to abolish pain. Nature. 2012;490(7421):552-5.

28. Waldmann $\mathrm{R}$, et al. The mammalian degenerin $M D E G$, an amiloride-sensitive cation channel activated by mutations causing neurodegeneration in Caenorhabditis elegans. J Biol Chem. 1996;271(18):10433-6.

29. Price MP, Snyder PM, Welsh MJ. Cloning and expression of a novel human brain Na+ channel. J Biol Chem. 1996;271(14):7879-82

30. Price MP, et al. The mammalian sodium channel BNC1 is required for normal touch sensation. Nature. 2000:407(6807):1007-11.

31. Peng BG, et al. Acid-sensing ion channel 2 contributes a major component to acid-evoked excitatory responses in spiral ganglion neurons and plays a role in noise susceptibility of mice. J Neurosci. 2004;24(45):10167-75.

32. Garcia-Anoveros J, et al. Transport and localization of the DEG/ENaC ion channel $\mathrm{BNaC1}$ alpha to peripheral mechanosensory terminals of dorsal root ganglia neurons. J Neurosci. 2001;21(8):2678-86.

33. Montano $\mathrm{JA}$, et al. The expression of $\mathrm{ENa}(+) \mathrm{C}$ and $\mathrm{ASIC} 2$ proteins in Pacinian corpuscles is differently regulated by TrkB and its ligands BDNF and NT-4. Neurosci Lett. 2009:463(2):114-8.

34. Lu Y, et al. The ion channel ASIC2 is required for baroreceptor and autonomic control of the circulation. Neuron. 2009:64(6):885-97.

35. Gannon KP, et al. Impaired pressure-induced constriction in mouse middle cerebral arteries of ASIC2 knockout mice. Am J Physiol Heart Circ Physiol. 2008;294(4):H1793-803.

36. Rahman F, et al. Detection of acid-sensing ion channel 3 (ASIC3) in periodontal Ruffini endings of mouse incisors. Neurosci Lett. 2011;488(2):173-7.

37. Wu WL, et al. Mice lacking Asic3 show reduced anxiety-like behavior on the elevated plus maze and reduced aggression. Genes Brain Behav. 2010;9(6):603-14.

38. Price MP, et al. The DRASIC cation channel contributes to the detection of cutaneous touch and acid stimuli in mice. Neuron. 2001:32(6):1071-83.

39. Molliver DC, et al. ASIC3, an acid-sensing ion channel, is expressed in metaboreceptive sensory neurons. Mol Pain. 2005;1:35.

40. Lin $\mathrm{SH}$, et al. Evidence for the involvement of ASIC3 in sensory mechanotransduction in proprioceptors. Nat Commun. 2016;7:11460.

41. Tong J, et al. Acid-sensing ion channels contribute to the effect of acidosis on the function of dendritic cells. J Immunol. 2011;186(6):3686-92.

42. Ikeuchi M, et al. Role of ASIC3 in the primary and secondary hyperalgesia produced by joint inflammation in mice. Pain. 2008;137(3):662-9.

43. Akopian AN, et al. A new member of the acid-sensing ion channel family. Neuroreport. 2000;11(10):2217-22

44. Lin SH, et al. Genetic mapping of ASIC4 and contrasting phenotype to ASICla in modulating innate fear and anxiety. Eur J Neurosci. 2015;41(12):1553-68.

45. Feldman $\mathrm{DH}$, et al. Characterization of acid-sensing ion channel expression in oligodendrocyte-lineage cells. Glia. 2008;56(11):1238-49.

46. Xiong ZG, et al. Neuroprotection in ischemia: blocking calcium-permeable acid-sensing ion channels. Cell. 2004;118(6):687-98. 
47. Yin T, et al. Loss of acid sensing ion channel-1a and bicarbonate administration attenuate the severity of traumatic brain injury. PLoS One. 2013;8(8):e72379.

48. Friese MA, et al. Acid-sensing ion channel-1 contributes to axonal degeneration in autoimmune inflammation of the central nervous system. Nat Med. 2007:13(12):1483-9.

49. Du J, et al. Protons are a neurotransmitter that regulates synaptic plasticity in the lateral amygdala. Proc Natl Acad Sci U S A. 2014;111(24):8961-6.

50. Coryell MW, et al. Targeting ASIC1a reduces innate fear and alters neuronal activity in the fear circuit. Biol Psychiatry. 2007;62(10):1140-8.

51. Ziemann AE, et al. The amygdala is a chemosensor that detects carbon dioxide and acidosis to elicit fear behavior. Cell. 2009;139(5):1012-21.

52. Kreple CJ, et al. Acid-sensing ion channels contribute to synaptic transmission and inhibit cocaine-evoked plasticity. Nat Neurosci. 2014;17(8): 1083-91.

53. Ziemann AE, et al. Seizure termination by acidosis depends on ASIC1a. Nat Neurosci. 2008;11(7):816-22.

54. Walder RY, et al. ASIC1 and ASIC3 play different roles in the development of hyperalgesia after inflammatory muscle injury. J Pain. 2010;11(3):210-8.

55. Roza C, et al. Knockout of the ASIC2 channel in mice does not impair cutaneous mechanosensation, visceral mechanonociception and hearing. J Physiol. 2004;558(Pt 2):659-69.

56. Omerbasic D, et al. ASICs and mammalian mechanoreceptor function. Neuropharmacology. 2015;94:80-6.

57. Lin YW, et al. Identification and characterization of a subset of mouse sensory neurons that express acid-sensing ion channel 3. Neuroscience. 2008;151(2):544-57.

58. Deval $\mathrm{E}$, et al. ASIC3, a sensor of acidic and primary inflammatory pain. EMBO J. 2008;27(22):3047-55.

59. Su YS, et al. Peripheral 5-HT3 mediates mirror-image pain by a cross-talk with acid-sensing ion channel 3. Neuropharmacology. 2018;130:92-104.

60. Chen WN, Chen CC. Acid mediates a prolonged antinociception via substance $P$ signaling in acid-induced chronic widespread pain. Mol Pain. 2014;10:30.

61. Sluka KA, et al. Chronic hyperalgesia induced by repeated acid injections in muscle is abolished by the loss of ASIC3, but not ASIC1. Pain. 2003;106(3): 229-39.

62. Lin CC, et al. An antinociceptive role for substance $P$ in acid-induced chronic muscle pain. Proc Natl Acad Sci U S A. 2012;109(2):E76-83.

63. Sluka KA, et al. ASIC3 in muscle mediates mechanical, but not heat, hyperalgesia associated with muscle inflammation. Pain. 2007;129(1-2):102-12.

64. Yen YT, et al. Role of acid-sensing ion channel 3 in sub-acute-phase inflammation. Mol Pain. 2009;5:1.

65. Cheng C-F, et al. Acid-sensing Ion Channel 3, but not capsaicin receptor TRPV1, plays a protective role in isoproterenol-induced myocardial ischemia in mice. Circ J. 2011;75(1):174-8.

66. Deval $\mathrm{E}$, et al. Acid-sensing ion channels in postoperative pain. J Neurosci. 2011:31(16):6059-66

67. Hsieh WS, et al. TDAG8, TRPV1, and ASIC3 involved in establishing hyperalgesic priming in experimental rheumatoid arthritis. Sci Rep. 2017; 7(1):8870.

68. Borzan J, et al. A role for acid-sensing ion channel 3, but not acid-sensing ion channel 2, in sensing dynamic mechanical stimuli. Anesthesiology. 2010; 113(3):647-54

69. Chen CC, et al. A role for ASIC3 in the modulation of high-intensity pain stimuli. Proc Natl Acad Sci U S A. 2002;99(13):8992-7.

70. Jones RC 3rd. L. Xu, and G.F. Gebhart, the mechanosensitivity of mouse colon afferent fibers and their sensitization by inflammatory mediators require transient receptor potential vanilloid 1 and acid-sensing ion channe 3. J Neurosci. 2005;25(47):10981-9.

71. Bielefeldt K, Davis BM. Differential effects of ASIC3 and TRPV1 deletion on gastroesophageal sensation in mice. Am J Physiol Gastrointest Liver Physiol. 2008;294(1):G130-8.

72. Lee $\mathrm{CH}$, et al. Role of the acid-sensing ion channel 3 in blood volume control. Circ J. 2011;75(4):874-83.

73. Fromy $B$, et al. Asic3 is a neuronal mechanosensor for pressure-induced vasodilation that protects against pressure ulcers. Nat Med. 2012;18(8): 1205-7.

74. Hildebrand MS, et al. Characterisation of DRASIC in the mouse inner ear. Hear Res. 2004;190(1-2):149-60.
75. Wu WL, et al. Asic3(-/-) female mice with hearing deficit affects social development of pups. PLoS One. 2009;4(8):e6508.

76. Donier $\mathrm{E}$, et al. Regulation of ASIC activity by ASIC4-new insights into ASIC channel function revealed by a yeast two-hybrid assay. Eur J Neurosci. 2008; 28(1):74-86

77. Kang S, et al. Simultaneous disruption of mouse ASIC1a, ASIC2 and ASIC3 genes enhances cutaneous mechanosensitivity. PLoS One. 2012;7(4):e35225.

78. Mamet J, et al. Proinflammatory mediators, stimulators of sensory neuron excitability via the expression of acid-sensing ion channels. J Neurosci. 2002; 22(24):10662-70.

79. Gonzales EB, Kawate T, Gouaux E. Pore architecture and ion sites in acidsensing ion channels and P2X receptors. Nature. 2009:460(7255):599-604.

80. Deval $E$, et al. Effects of neuropeptide SF and related peptides on acid sensing ion channel 3 and sensory neuron excitability. Neuropharmacology. 2003;44(5):662-71.

81. Qin F. Hill coefficients of a polymodal Monod-Wyman-Changeux model for ion channel gating. Biophys J. 2010;99(3):L29-31.

82. Salinas M, Lazdunski M, Lingueglia E. Structural elements for the generation of sustained currents by the acid pain sensor ASIC3. J Biol Chem. 2009; 284(46):31851-9.

83. Springauf A, Bresenitz P, Grunder S. The interaction between two extracellular linker regions controls sustained opening of acid-sensing ion channel 1. J Biol Chem. 2011;286(27):24374-84.

84. Vullo $\mathrm{S}$, et al. Conformational dynamics and role of the acidic pocket in ASIC pH-dependent gating. Proc Natl Acad Sci U S A. 2017;114(14):3768-73.

85. Li WG, XU TL. ASIC3 channels in multimodal sensory perception. ACS Chem Neurosci. 2011;2(1):26-37.

86. $\mathrm{Yu} Y$, et al. A nonproton ligand sensor in the acid-sensing ion channel. Neuron. 2010;68(1):61-72

87. Wang W, et al. Calcium-permeable acid-sensing ion channel is a molecular target of the neurotoxic metal ion lead. J Biol Chem. 2006;281(5):2497-505.

88. Marra S, et al. Non-acidic activation of pain-related acid-sensing lon Channe 3 by lipids. EMBO J. 2016;35(4):414-28.

89. Smith ES, Cadiou H, McNaughton PA. Arachidonic acid potentiates acidsensing ion channels in rat sensory neurons by a direct action. Neuroscience. 2007;145(2):686-98.

90. Osmakov DI, et al. Endogenous Isoquinoline alkaloids agonists of acidsensing lon Channel type 3. Front Mol Neurosci. 2017;10:282.

91. Osmakov Dl, et al. Proton-independent activation of acid-sensing ion channel 3 by an alkaloid, lindoldhamine, from Laurus nobilis. Br J Pharmacol. 2018;175(6):924-37.

92. Bangsbo J, et al. Lactate and $\mathrm{H}+$ effluxes from human skeletal muscles during intense, dynamic exercise. J Physiol. 1993;462:115-33.

93. Immke DC, McCleskey EW. ASIC3: a lactic acid sensor for cardiac pain ScientificWorldJournal. 2001;1:510-2.

94. Yagi J, et al. Sustained currents through ASIC3 ion channels at the modest $\mathrm{pH}$ changes that occur during myocardial ischemia. Circ Res. 2006:99(5):501-9.

95. Benson CJ, Eckert SP, McCleskey EW. Acid-evoked currents in cardiac sensory neurons: a possible mediator of myocardial ischemic sensation. Circ Res. 1999;84(8):921-8.

96. Hattori T, et al. ASIC2a and ASIC3 heteromultimerize to form $\mathrm{pH}$-sensitive channels in mouse cardiac dorsal root ganglia neurons. Circ Res. 2009; 105(3):279-86.

97. Chalfie M. Neurosensory mechanotransduction. Nat Rev Mol Cell Biol. 2009; 10(1):44-52.

98. Goodman MB, Schwarz EM. Transducing touch in Caenorhabditis elegans. Annu Rev Physiol. 2003;65:429-52.

99. Chalfie M, Sulston J. Developmental genetics of the mechanosensory neurons of Caenorhabditis elegans. Dev Biol. 1981;82(2):358-70.

100. Driscoll $M$, Chalfie $M$. The mec- 4 gene is a member of a family of Caenorhabditis elegans genes that can mutate to induce neuronal degeneration. Nature. 1991;349(6310):588-93.

101. Goodman MB, et al. MEC-2 regulates C. Elegans DEG/ENaC channels needed for mechanosensation. Nature. 2002;415(6875):1039-42.

102. $\mathrm{Hu} \mathrm{J}$, et al. Evidence for a protein tether involved in somatic touch. EMBO J. 2010:29(4):855-67.

103. Moshourab RA, et al. Stomatin-domain protein interactions with acidsensing ion channels modulate nociceptor mechanosensitivity. J Physiol. 2013;591(22):5555-74 
104. Wetzel C, et al. A stomatin-domain protein essential for touch sensation in the mouse. Nature. 2007;445(7124):206-9.

105. Duggan A, Garcia-Anoveros J, Corey DP. The PDZ domain protein PICK1 and the sodium channel $\mathrm{BNaC1}$ interact and localize at mechanosensory terminals of dorsal root ganglion neurons and dendrites of central neurons. J Biol Chem. 2002;277(7):5203-8.

106. Hruska-Hageman AM, et al. Interaction of the synaptic protein PICK1 (protein interacting with $C$ kinase 1 ) with the non-voltage gated sodium channels BNC1 (brain Na+ channel 1) and ASIC (acid-sensing ion channel). Biochem J. 2002;361(Pt 3):443-50.

107. Deval E, et al. ASIC2b-dependent regulation of ASIC3, an essential acidsensing ion channel subunit in sensory neurons via the partner protein PICK-1. J Biol Chem. 2004;279(19):19531-9.

108. Jin W, et al. PICK1 regulates the trafficking of ASIC1a and acidotoxicity in a BAR domain lipid binding-dependent manner. Mol Brain. 2010;3:39.

109. Anzai N, et al. The multivalent PDZ domain-containing protein CIPP is a partner of acid-sensing ion channel 3 in sensory neurons. J Biol Chem. 2002; 277(19):16655-61.

110. de Nooij JC, et al. The PDZ-domain protein Whirlin facilitates mechanosensory signaling in mammalian proprioceptors. J Neurosci. 2015;35(7):3073-84.

111. Lin YW, et al. Understanding sensory nerve mechanotransduction through localized elastomeric matrix control. PLoS One. 2009;4(1):e4293.

112. Khalsa PS, et al. Integrin alpha2beta1 affects mechano-transduction in slowly and rapidly adapting cutaneous mechanoreceptors in rat hairy skin. Neuroscience. 2004;129(2):447-59.

113. Chiang LY, et al. Laminin-332 coordinates mechanotransduction and growth cone bifurcation in sensory neurons. Nat Neurosci. 2011;14(8):993-1000.

114. Drew LJ, et al. Acid-sensing ion channels ASIC2 and ASIC3 do not contribute to mechanically activated currents in mammalian sensory neurones. J Physiol. 2004;556(Pt 3):691-710.

115. Kung C. A possible unifying principle for mechanosensation. Nature. 2005; 436(7051):647-54

116. Coste B, et al. Piezo1 and Piezo2 are essential components of distinct mechanically activated cation channels. Science. 2010;330(6000):55-60.

117. Cheng $\mathrm{CM}$, et al. Probing localized neural mechanotransduction through surface-modified elastomeric matrices and electrophysiology. Nat Protoc. 2010;5(4):714-24.

118. Murthy SE, Dubin AE, Patapoutian A. Piezos thrive under pressure: mechanically activated ion channels in health and disease. Nat Rev Mol Cell Biol. 2017;18(12):771-83.

119. Qi Y, et al. Membrane stiffening by STOML3 facilitates mechanosensation in sensory neurons. Nat Commun. 2015;6:8512.

120. Dubin $A E$, et al. Inflammatory signals enhance piezo2-mediated mechanosensitive currents. Cell Rep. 2012;2(3):511-7.

121. Arnadottir J, et al. The DEG/ENaC protein MEC-10 regulates the transduction channel complex in Caenorhabditis elegans touch receptor neurons. J Neurosci. 2011;31(35):12695-704.

122. Woo SH, et al. Piezo2 is the principal mechanotransduction channel for proprioception. Nat Neurosci. 2015;18(12):1756-62.

123. Florez-Paz D, et al. A critical role for Piezo2 channels in the mechanotransduction of mouse proprioceptive neurons. Sci Rep. 2016;6:25923.

124. Anderson EO, Schneider ER, Bagriantsev SN. Piezo2 in cutaneous and proprioceptive Mechanotransduction in vertebrates. Curr Top Membr. 2017: 79:197-217.

125. Dusenkova $\mathrm{S}$, et al. The expression profile of acid-sensing ion channel (ASIC) subunits ASIC1a, ASIC1b, ASIC2a, ASIC2b, and ASIC3 in the esophageal vagal afferent nerve subtypes. Am J Physiol Gastrointest Liver Physiol. 2014;307(9): G922-30.

126. Simon A, et al. Amiloride-sensitive channels are a major contributor to mechanotransduction in mammalian muscle spindles. J Physiol. 2010;588 (Pt 1):171-85.

127. Page AJ, et al. The ion channel ASIC1 contributes to visceral but not cutaneous mechanoreceptor function. Gastroenterology. 2004;127(6): 1739-47.

128. Diochot $S$, Alloui A, Rodrigues $P$, Dauvois M, Friend V, Aissouni Y, Eschalier A, Lingueglia E, Baron A. Analgesic effects of mambalgin peptide inhibitors of acid-sensing ion channels in inflammatory and neuropathic pain. Pain. 2016;157(3):552-9.

129. Wang IC, Chung CY, Liao F, Chen CC, Lee CH. Peripheral sensory neuron injury contributes to neuropathic pain in experimental autoimmune encephalomyelitis. xSci Rep. 2017;7:42304.
130. Vergo S, Craner MJ, Etzensperger R, Attfield K, Friese MA, Newcombe J, Esiri M, Fugger L. Acid-sensing ion channel 1 is involved in both axonal injury and demyelination in multiple sclerosis and its animal model. Brain. 2011; 134(Pt 2):571-84.

131. Zeng WZ, Liu DS, Duan B, Song XL, Wang X, Wei D, Jiang W, Zhu MX, Li Y, $\mathrm{Xu}$ TL. Molecular mechanism of constitutive endocytosis of acid-sensing ion channel 1a and its protective function in acidosis-induced neuronal death. $J$ Neurosci. 2013;33(16):7066-78.

132. Jiang Q, Wang CM, Fibuch EE, Wang JQ, Chu XP. Differential regulation of locomotor activity to acute and chronic cocaine administration by acidsensing ion channel 1a and 2 in adult mice. Neuroscience. 2013;246:170-8.

133. Wemmie JA, Chen J, Askwith CC, Hruska-Hageman AM, Price MP, Nolan BC, Yoder PG, Lamani E, Hoshi T, Freeman JH Jr, Welsh MJ. The acid-activated ion channel ASIC contributes to synaptic plasticity, learning, and memory. Neuron. 2002:34(3):463-77.

134. Wu PY, Huang YY, Chen CC, Hsu TT, Lin YC, Weng JY, Chien TC, Cheng IH, Lien CC. Acid-sensing ion channel-1a is not required for normal hippocampal LTP and spatial memory. J Neurosci. 2013;33(5):1828-32.

\section{Ready to submit your research? Choose BMC and benefit from:}

- fast, convenient online submission

- thorough peer review by experienced researchers in your field

- rapid publication on acceptance

- support for research data, including large and complex data types

- gold Open Access which fosters wider collaboration and increased citations

- maximum visibility for your research: over $100 \mathrm{M}$ website views per year

At BMC, research is always in progress.

Learn more biomedcentral.com/submissions 